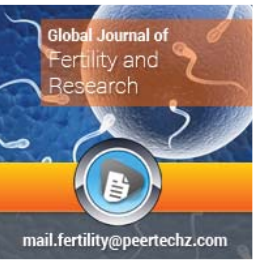

\title{
Global Journal of Fertility and Research
}

Momina Abdella', Araya Abraha ${ }^{2}$, Abel Gebre $^{3}$ and P Surender Reddy $4 *$

'Health expert, afar regional state health Bureau, Samara, Ethiopia

${ }^{2}$ Assistant Professor. School of Public Health, College of Health Sciences, Mekelle University, Ethiopia

${ }^{3}$ Lecturer, Department of Public Health, College Medicine \& Health Sciences, Samara University, Ethiopia

${ }^{4}$ Professor, Department of Public Health, College Medical \& Health Sciences, Samara University, Ethiopia

Dates: Received: 20 May, 2017; Accepted: 30 August, 2017; Published: 31 August, 2017

*Corresponding author: P Surender Reddy, Professor, Department of Public Health, 406,Banjarasadan,

14th street, Himayathnagar, Hyderabad, India, Tel: +919346977000;

E-mail: dr.surenderreddy@yahoo.com;

surenderreddy1956@gmail.com

Keywords: Delivery; Factors; Assaita; Delivery

https://www.peertechz.com
Research Article

Magnitude and Associated Factors

for Home Delivery Among Women

Who Gave Birth in Last 12 Months

in Ayssaita, Afar, Ethiopia-2016. A

community Based Cross Sectional

Study

\section{Abstract}

Introduction: Proper medical attention and hygienic conditions during delivery can reduce the risk of complications and infections that can cause the death or serious illness of the mother or newborn baby. Home deliveries are common in developing Home deliveries range from $22 \%$ in Senegal, $65 \%$ in Tanzania, $87.7 \%$ in Bangladesh and $94 \%$ in Ethiopia.

Objective: To assess the magnitude and factors associated with home delivery in Ayssaita district, Afar, Ethiopia, 2016.

Methods: A community based cross-sectional study was conducted in May2016 with 317 sample using structured questionnaire. Bivariate and multivariate analyses were conducted and Odds ratio with $95 \% \mathrm{Cl}$ and $\mathrm{p}$ value of $<0.05$ for statistical significance were declared.

Results: About $71.0 \%$ of women delivered at home and majority of them were assisted by nonskilled attendants (75.4\%). The independent predictors for home delivery in this study were maternal age, maternal residence, maternal education and maternal awareness on at least one danger signs during pregnancy.

Conclusion: Majority of women $(74.4 \%)$ attended at least one antenatal visit from skilled health care providers during their recent pregnancy however; majority of them gave birth at home $(71.0 \%)$ and assisted by non-skilled attendant. Being rural resident, illiterate, younger age, and not having least awareness on at least one danger signs were the independent predictors for home delivery. Women empowerment through educational opportunities; strengthening health extension workers to create community awareness on the importance of institutional delivery particularly for the rural pastoralist mothers are recommended.

\section{Introduction}

In spite of global efforts to reduce maternal mortality, the World Health Organization (WHO) reports that the global maternal mortality ratio (i.e., the number of maternal deaths per 100,000 live births) declined only $2.3 \%$ per year between 1990 and 2008. This is far from the annual decline of $5.5 \%$ required to achieve the fifth Millennium Development Goal (MDG) [1]. Wide disparities respectively are found among regions in the level of skilled attendance at birth-ranging from $100 \%$ and 97\% in Eastern Asia and Central Asia respectively and it is about 50\% in Southern Asia and sub-Saharan Africa [2].
Health problems during pregnancy may have serious consequences for the woman, her child, her family, and her community. Maternal health has emerged as global priority because of a great gap in the status of mother's wellbeing between rich and the poor countries. In developing countries, many women suffer from the ill health during pregnancy and child birth [3].

Although most pregnancies and births are uneventful, approximately $15 \%$ of all pregnant women develop a potentially life-threatening Complication that calls for skilled care and some will require a major obstetrical intervention to Survive. If 
Emergency Obstetric Care is available, and women can access it in time, women's lives can be saved [4].

Each year around four million newborns die in the first week of life, worldwide, an estimated 529,000 mother's die due to pregnancy-related causes. In low and middle-income countries many deliveries still occur at home and without the assistance of trained attendants [5]. This has generated serious concern, since women who develop life-threatening complications during pregnancy and delivery require appropriate and accessible care. The major causes of maternal death in low income countries include obstructed labor, ruptured uterus, severe pre-eclampsia/eclampsia, malaria and complications from abortion [6,7]. Home deliveries are common in developing countries. Studies in some countries have reported that home deliveries range from $22 \%$ in Senegal to $65 \%$ in Tanzania and to $87.7 \%$ in Bangladesh $[8,9]$.

In Ethiopia $94 \%$ of births take place at home without the assistance of trained persons. Of these, $28 \%$ are assisted by Traditional Birth Attendants (TBAs), $61 \%$ by relatives or others and $5 \%$ are delivered without any type of assistance at all [10]. The Ethiopian Demographic and Health Survey(EDHS) 2011 shows that home delivery comprises $90 \%$ of all deliveries in the country, regardless of expansion of strategies to increase service utilization and to improve maternal and child health [11].Small studies in different regions of the country also support this figure 1. Similar to studies conducted Bangladesh and Nigeria, small studies in Ethiopia show that the most frequent reasons for high rates of home delivery are distance to health facility, problems in transportation, lack of decision making power among women, low levels of antenatal care (ANC), and cost for medical care , poor educational attainment $[1,12,13]$.

Ethiopia is one of the ten countries that comprised $58 \%$ of global maternal deaths estimated in 2013. Based on data in the 2011 Ethiopia Demographic and Health Survey, the MMR was estimated at 676 maternal deaths per 100,000 live births [11]. This makes it very difficult to achieve the Millennium Development Goal. The risk of dying from pregnancy in Africa is 1 in 16; in Asia, 1 in 65; and in North America, 1 in 3,700. The overall risk for developing countries is 1 in 48, whereas in industrial countries the risk is 1 in 1,800 [14].

Different reasons account for the high Maternal Mortality Ratio (MMR) in sub-Saharan African countries, including Ethiopia. A lack of decision-making power among women within the family remains a challenge in many countries $[15,16]$. Low levels of female education and little availability of medical services during pregnancy prevent women receiving care and accessing the best choices for themselves and their children's health, resulting in critical delays in receiving care and unnecessary maternal complications and deaths $[16,17]$.

Globally both child and maternal mortality have dropped dramatically since 1990. Maternal deaths have declined from 543,000 per 100,000 live births in 1990 to 287,000 in 2010 [18].

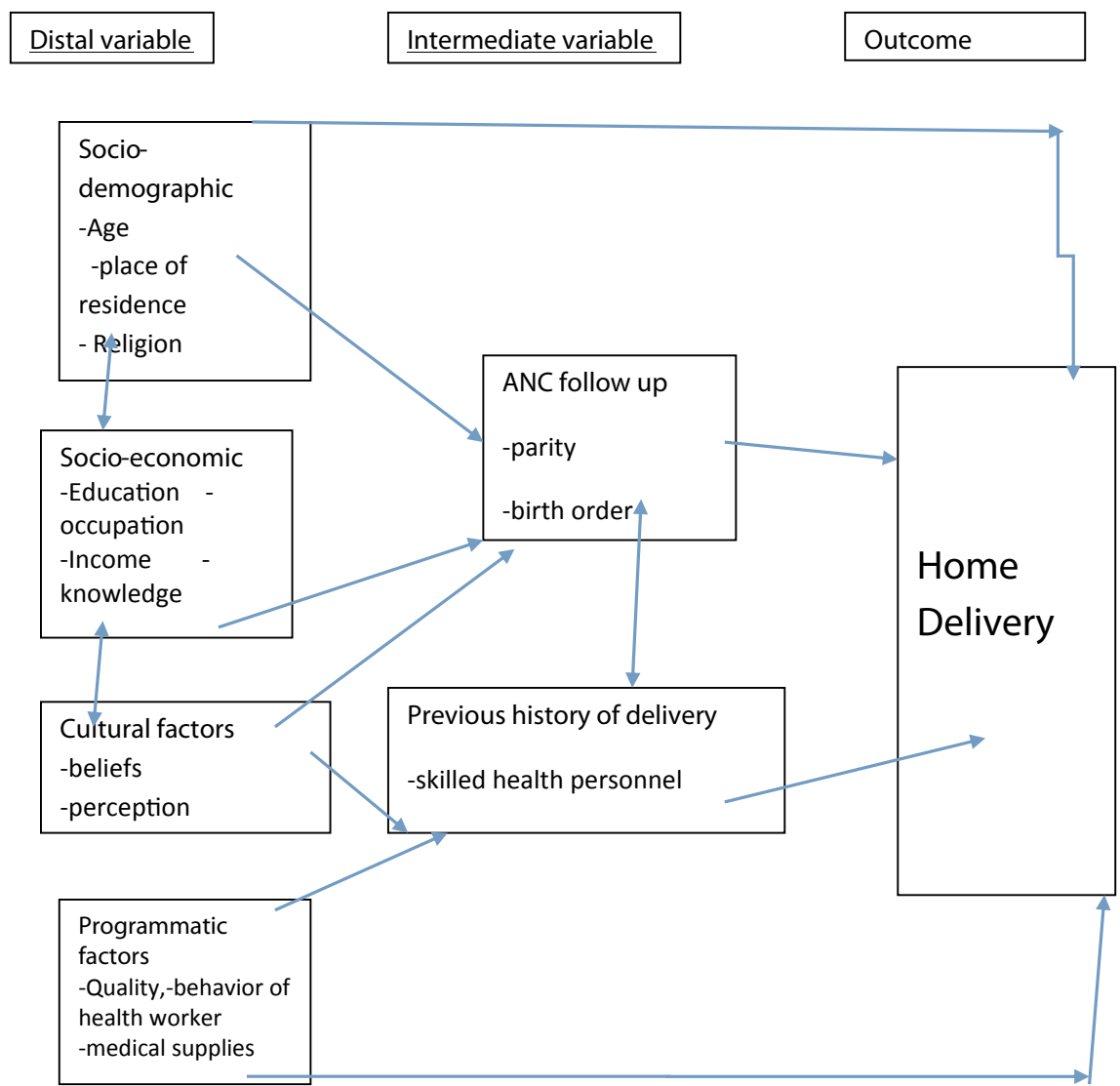


Globally, an estimated $42 \%$ of maternal deaths are intra partum related, that is during birth or the first day after birth in which majority of this occurs in developing countries. Intra partum-related neonatal death is a key issue during delivery in which almost all intra partum-related neonatal deaths occur in low- and middle-income countries particularly South Asia and Africa with large numbers $73 \%$ of all intra partum-related neonatal deaths worldwide. Ethiopia is one of the 10 countries that contribute more than $65 \%$ of all intra partum related deaths including: India, China, Democratic Republic of Congo, Pakistan, Nigeria, Bangladesh, Indonesia, Afghanistan, and Tanzania [19].

In one of the Amhara regional state district of Ethiopia as per 2012 study, $48.3 \%$ gave their last birth in health institutions and $51.7 \%$ gave birth at home [20].

Data analysis from 2011 EDHS with a sample from 576 communities of 7,908 women whose most recent births were within five years preceding the survey in Ethiopia showed that $88 \%$ of deliveries took place at home [21].

Demographic and Health Survey(DHS) analysis done in 2011 shows only $6 \%$ of women who delivered in the five years preceding the survey were assisted by a health professional for their most recent pregnancy [22]. Even if institutional delivery increases from $10 \%$ in 2011 to $15 \%$ in 2014 it is very low comparing with other countries [11,23].

Several studies have been conducted Worldwide on the factors affecting delivery in health facilities and the following was observed, The issues of risk and vulnerability, such as lack of money, lack of transport, sudden onset of labour, short labour, staff attitudes, lack of privacy, geographical location, perception of poor quality of health services, tradition, cultures and the pattern of decision-making power within the household were perceived as key determinants of the place of delivery [24-27].

A secondary data analysis of the third (2005) Rwandan Demographic Health Survey shows although more than $90 \%$ of participants attended an antenatal service, only $30 \%$ delivered at a health facility. [28].

A study conducted in Gondar, North Ethiopia in 2012 revealed that women having at least one skilled antenatal care in their recent pregnancy were about two times more likely to have birth attendance by a skilled provider [29]. In similar way, study conducted in Woldia, Ethiopia in 2012 revealed that women who attended Ant Natal Care (ANC) four times were more likely to utilize skilled delivery compared to women who attended 1-3 times during pregnancy [30].

A Community based cross sectional study in Goba woreda in 2013 indicates that factors were found to be associated with institutional delivery were residential place, educational level of mothers and husbands, ANC follow up and being birth prepared and ready for its complication. [31].

Similar study done in Tigray region in 2012shows Women in the younger age group had the highest proportion of institutional delivery use (54\%) followed by the middle age group, 30-39 years (39\%). Moreover, women with 5-12 years of education were more likely to use institutional delivery than non-educated mothers [32].

A study conducted in 2004 in Ethiopia Afar, Dubti, Ayssaita town indicated that as order of pregnancy and parity of the first time preferences to delivery at institution were more likely than those who have order of pregnancy and parity of five or more [33].

These factors could also influence women's decision to give birth at home rather than in a health facility. Urban are notably more likely than rural births to be delivered in a health facility $(50 \%$ versus $4 \%)$. The $\%$ of births delivered in health facility ranges from less than $10 \%$ in Afar, South Nationality Nations Peoples Region (SNNPR), Oromiya, Somalia, and BenishangulGumuz regions to $82 \%$ in Addis. Previous qualitative study in Afar was reported that most mothers deliver at home, assisted by Traditional Birth Attendants (TBAs) [12]. However, determinant factors of delivery practices in this region remain scarcely explored. So this study finding will be useful to concerned stake holders in planning, implementing and evaluating various interventions to reduce maternal and neonatal mortality rate.

This Conceptual framework is adopted from different literatures to investigate factors associated with home delivery. It indicates the relation between home delivery and different direct and indirect associated factors for home delivery in the study area. All these factors are leading to Home delivery and strength of association is explained in analysis part.

\section{General objective}

To assess the magnitude and associated factors for home delivery among women of reproductive age who gave birth in the last 12 months preceding the survey in Ayssaita district Afar, Ethiopia - 2016

\section{Methods and Materials}

\section{Study area and period}

The study area is Ayssaita district located in zone one, Afar region North East Ethiopia. It is about $700 \mathrm{Km}$ from Addis Ababa with an estimated population of 64,393 of which 34,382 are males and 30, 011 females and the expected numbers of pregnant women are 2576 (CSA; 2011). The District is subdivided into 2 urban and 11 rural villages. The district though it is found in pastoralist region; it has a relatively settled population. However, the utilization of health services in general and maternal healthcare service in particular is very low even lower than the national average. As per EDHS 2011 the antenatal and delivery care in Afar region was 32.3\% and 6.6\% respectively. The study was conducted from May 10- 30, 2016 with Community based cross-sectional design.

\section{Source population}

All reproductive age women who gave birth in the last twelve months in the Ayssaita district, afar, Ethiopia. 


\section{Specific objectives:}

To determine the magnitude of home delivery practice in Ayssaita district.

$\checkmark$ To identify factors that influence women's practicing home delivery in Ayssaita district.

\section{Study population}

Selected women who gave birth during a one year period preceding the study and residing in the district.

Exclusion Criteria: Women, who are critically ill, couldn't talk or listen.

\section{Sample size determination}

318 samples were selected by using single population proportion formula based on the assumptions: in the previous prevalence data on the population under study, p was 0.936 with $4 \%$ margin of error and $95 \%$ confidence level of certainty.

\section{Sampling procedure}

Multi-stage sampling technique was applied to select study subjects. The district was divided into urban and rural village. Urban consists of two areas and the rural consists of elevenvillages. One area from urban, four villages from rural district were identified using simple random sampling method. Pre-survey was conducted to identify the elibible households for the survey. Then, sampling fraction for each of the selected kebeles was determined by probability proportional sampling method and then used systematic random sampling technique to reach each sample households and $\mathrm{k}^{\text {th }}$ household with eligible mother was included in the study. Whenever more than one eligible respondent was present in the same selected household, only one respondent was chosen by lottery method (simple random sampling).

\section{Dependent Variable: Home delivery practice (yes/no).}

Independent Variables: Socio demographic characteristics like age, religion, education level, marital status, parity, and head of household, size of the family, women occupation and husband occupation, socio economic, cultural and so on.

Data Collection Tools: Data was collected by using pretested structured interviewer administered questionnaire.

\section{Data management, analysis and interpretation}

Data was entered in to EPIdata 3.0 and transported to SPSS Version2o for further processing and computation. Frequencies, percentages and summary statistics were computed to describe the study population in relation to relevant variables. Bivariate analysis using cross tabulation was done to see the association between each independent variables and the outcome interest (home delivery practice) and crude odds ratio (COR) with 95\% CI was obtained. Then, variables observed in the bivariate analysis with ( $\mathrm{p}$-value $<0.2)$ was subsequently included in to the final models of multivariable logistic regression to control for possible confounding effect and to assess the separate effects of each variable on the outcome variable (home delivery practice). The strength of statistical association was measured by adjusted odds ratios (AOR) and 95\% confidence intervals (CI). All tests were two-sided and $\mathrm{p}<0.05$ was considered statistically significant.

Ethical Consideration: ethical clearance and permissions to carry out the study were obtained from the concerned authorities and participants were assured for confidentiality and right to withdraw from the study.

\section{Results and Discussion}

\section{Socio-demographic characteristics of the respondents}

Total sample was 317 with response rate of $99.7 \%$. The mean ages $(+\mathrm{SD})$ of the respondents' was $26.61+4.4$. Majority of them were Muslims (93.4\%) and Majority of them were married (93.4\%). 212(66.9\%) of the respondents never attended formal school and, 47(14.8\%) of women attended elementary education whereas, 33(10.4\%) women attended secondary and above education. Majority of the respondents' occupation was house wife (94.3\%) (Table 1).

\section{Obstetrics characteristics of the respondents}

The mean ages (+SD) of the respondents' during first pregnancy and gestational age at first ANC visit was $20.12+$ 2.5 years and $15.2+2.8$ weeks respectively. $84.2 \%$ were with intended pregnancy whereas, $15.8 \%$ were unintended (either unwanted or mistimed) and $74.4 \%$ of them attended antenatal care (Table 2). Only $46.1 \%$ of the respondents were aware at least one obstetric danger sign during recent pregnancy while, more than half ( $53.9 \%$ ) were not aware at all. concerning about not attending of ANC service, more than half, reported that being in a state of healthy $(60.5 \%)$, very far from health facility $(8.6 \%)$, due to too busy (9.9\%), not knowing the importance of antenatal care use $(2.5 \%)$, afraid of the cost $(1.2 \%)$, feel shame to attend ANC $(4.9 \%)$ and reported poor quality of the service (7.4\%).

\section{Magnitude of home and institutional delivery}

$236(74.4 \%)$ of them attended at least one antenatal visit during their last pregnancy. The majority of the participants $(83.1 \%)$ used their first antenatal visit below sixteen weeks of pregnancy (Table 2). 225 (71.0\%) of the interviewed women delivered in their home and assisted by non-skilled health professionals: including, traditional birth attendants $(26.1 \%)$, mother $(39.3 \%)$, health extension workers $(24.6 \%)$ and other relatives $(9.5 \%) .92(29.0 \%)$ of the respondents delivered at health facility and assisted by skilled health professional. Regarding the reasons for not utilizing the health facility for delivery, $37.8 \%$ of women reported no health problem to attend delivery care, $31.1 \%$ said far distance from health facility, $15.1 \%$ said poor quality of service, and $6.2 \%$ of the women reported no female health worker (Table 3).

Socio demographic factors associated with home delivery

Mother's age, residence, mother's education and husband's occupation were significantly associated with home delivery. 
Women's age less than 25 years was 2.3 times more likely to use home delivery as compared to women age more than 25 years $(\mathrm{COR}=2.28,95 \% \mathrm{CI}=1.32,3.94)$. Women living in rural areas were 8.2 times more likely to deliver at their home than urban dwellers $(\mathrm{COR}=8.23,95 \% \mathrm{CI}=4.31=15.71)$. Women with

Table 1: Socio-demographic characteristics of the mother's in Aysaita district, Afar region, North Eastern, Ethiopia, $2016(\mathrm{n}=317)$.

\begin{tabular}{|c|c|c|}
\hline Variable (s) & Frequency( $n=317)$ & Percentage (\%) \\
\hline \multicolumn{3}{|l|}{ Mother's Age (years) } \\
\hline $15-19$ & 33 & 10.4 \\
\hline $20-24$ & 83 & 26.2 \\
\hline $25-29$ & 91 & 28.7 \\
\hline $30-34$ & 102 & 32.2 \\
\hline$>35$ & 8 & 2.5 \\
\hline \multicolumn{3}{|l|}{ Religion } \\
\hline Muslim & 296 & 93.4 \\
\hline Orthodox & 20 & 6.3 \\
\hline Others & 1 & 0.3 \\
\hline \multicolumn{3}{|l|}{ Ethnicity } \\
\hline Afar & 194 & 61.2 \\
\hline Amhara & 104 & 32.8 \\
\hline Oromo & 16 & 5.0 \\
\hline Others & 3 & 0.9 \\
\hline \multicolumn{3}{|l|}{ Residence } \\
\hline Rural & 263 & 83.0 \\
\hline Urban & 54 & 17.0 \\
\hline \multicolumn{3}{|l|}{ Educational status } \\
\hline Unable to read and write & 212 & 66.9 \\
\hline Only read and write & 25 & 7.9 \\
\hline Attended elementary school(1-8) & 47 & 14.8 \\
\hline Attended junior or senior high s & 24 & 7.6 \\
\hline Attended higher(tertiary)education & 9 & 2.8 \\
\hline \multicolumn{3}{|l|}{ Marital status } \\
\hline Currently Married & 296 & 93.4 \\
\hline Divorced & 9 & 2.8 \\
\hline Widowed & 9 & 2.8 \\
\hline Separated & 3 & 0.9 \\
\hline \multicolumn{3}{|l|}{ Occupational status } \\
\hline House wife & 299 & 94.3 \\
\hline Government employee & 17 & 5.4 \\
\hline Merchant & 1 & 0.3 \\
\hline \multicolumn{3}{|l|}{ Husband's educational status( $n=297)$} \\
\hline Unable to read and write & 143 & 45.1 \\
\hline Only read and write & 31 & 9.8 \\
\hline Attended elementary school(1-8) & 63 & 19.9 \\
\hline Attended junior or senior high s & 35 & 11.0 \\
\hline Attended higher(tertiary)education & 24 & 7.6 \\
\hline \multicolumn{3}{|l|}{ Husband's occupational status(n=297) } \\
\hline Pastoralist & 103 & 32.5 \\
\hline Government employee & 62 & 19.6 \\
\hline Merchant & 57 & 18.0 \\
\hline Non-governmental employee & 6 & 1.9 \\
\hline Others & 68 & 21.5 \\
\hline
\end{tabular}

no formal school were 2.1 times higher than women with formal education to give birth at their homes $(\mathrm{COR}=2.11,95 \%$ $\mathrm{CI}=1.24,3.61)($ Table-4).

\section{Maternal and obstetric factors associated with home delivery}

In the bivariate analysis, gravidity, parity, wanted pregnancy, attending ANC for the recent pregnancy, Gestational Age (GA) at first ANC service, number of live births, mother's awareness on at least one danger signs and history of facing any health problem during labor and delivery, were the factors associated with home delivery among the study participants (Table 5). Women who were Primigravida were 2.2 times more likely to deliver at home as compared to Multigravida women (COR=2.15, 95\% CI=1.09-4.25). Regarding parity, women who were primipara were 1.53 times more likely to deliver at home as compared to multiparaous women $(\mathrm{COR}=2.53,95 \% \mathrm{CI}=0.85$, 2.85).

At multivariable logistic regression analysis level after adjusting for each other, revealed that variables that were independent predictors for maternal home delivery are maternal age $(\mathrm{AOR}=2.959,95 \% \mathrm{CI}=1.076-8.133)$, maternal residence $(\mathrm{AOR}=7.29,95 \% \mathrm{CI}=6.89-13.41)$, maternal education $(\mathrm{AOR}=2.838,95 \% \mathrm{CI}=1.073-7.506)$ and maternal awareness on at least one danger signs during pregnancy (AOR=3.306, $95 \% \mathrm{CI}=1.346-8.119$ ) which could affect for home delivery among women who gave birth in the last 12 months period. However, husband's occupation, mother's gravidity, mother's parity, mother's want to the pregnancy, ANC follow up for the pregnancy, gestational age (GA) of ANC at first visit, number of livebirths, and history of facing any pregnancy related health problem in the previous were not statistically significantly associated with home delivery (Table 6).

Women who are less than 25 years old were 2.9 times more likely to deliver at home than women having age of greater than 25 years old $(\mathrm{AOR}=2.9,95 \% \mathrm{CI}=1.1-8.1)$. Women who are living in the rural were 7.3 times more likely to deliver at home than women living in the urban areas (AOR $=7.29,95 \%$ $\mathrm{CI}=6.89-13 \cdot 41)$. Participants who had no formal education 2.83 were more likely to deliver in their home than women who had formal education $(\mathrm{AOR}=2.83,95 \% \mathrm{CI}=1.1-7.5)$. This study indicated that women who had not awareness on at least one danger signs during pregnancy and delivery were 3.3 times more likely to be delivered in the home as compared to women who had some level of awareness on these danger signs $(\mathrm{AOR}=3.30,95 \% \mathrm{CI}=1.35,8.12)$.

Home deliveries are common in developing countries. Studies in some countries have reported that home deliveries range from $22 \%$ in Senegal to $65 \%$ in Tanzania and to $87.7 \%$ in Bangladesh. In Ethiopia, $94 \%$ of births take place at home without the assistance of trained persons $[8,9]$. So, the best way to assure a safe and successful delivery outcome remains to be ensuring the presence of a skilled birth attendant at every child birth. Therefore, this study was designed to assess magnitude of home delivery and associated factors among reproductive age group women (15-49 years) who gave birth in the last 12 months, Assaita district Afar region, North Eastern Ethiopia. 
Table 2: Obstetrics characteristics of the respondents in Aysaita district, Afar region, North Eastern, Ethiopia, $2016(n=317)$.

Variables

Frequency( $n=317)$ Percentage (\%)

Age of mother at first pregnancy

\begin{tabular}{|c|c|c|}
\hline$<18$ \\
\hline $18-24$ \\
$25-29$ \\
$30-34$ \\
$>35$ \\
\hline Gravidity \\
\hline Primigravida \\
\hline Multigravida \\
\hline Parity
\end{tabular}

\begin{tabular}{l|l} 
Primiparous & 71
\end{tabular}

Multiparous 246

No of live births

0-1

2-3

$>=4$

No still births

$$
0
$$$$
1
$$$$
>=2
$$

No of abortions

$$
0
$$

1

No of neonatal births

0

$>=2$

Wanted pregnancy

Yes

No

Attended ANC

Yes

No

Where did you attend $(n=236)$

Hospital

Health center

Health Post

Others

GA at first ANC service (In weeks)

$<=16$

$>16$

Frequency of ANC visit

$<4$

$>=4$

Reasons for not attending ANC $(n=81)$

No health problem

Too busy to attend ANC clinic

Health facility far

Husband refused

Afraid fee

Poor quality of the services
Do not know importance of ANC

4

ness on at least one danger sign during pregnancy and delivery

\begin{tabular}{|l|l}
\hline Yes & 146 \\
\hline No & 171 \\
\hline
\end{tabular}

Type of danger signs during pregnancy $(n=146)$

Severe vaginal bleeding during $p$ Swollen hands/face Severe headache

Absent fetal movement

Blurred vision

Severe vaginal bleeding during I

Pro-longed labor(>12 hours) Convulsions

\begin{tabular}{|c|c|}
\hline 48 & 15.1 \\
\hline 40 & 12.6 \\
\hline 18 & 5.7 \\
\hline 14 & 4.4 \\
\hline 15 & 4.7 \\
\hline 8 & 2.5 \\
\hline 1 & .3 \\
\hline 2 & .6 \\
\hline
\end{tabular}

\section{Magnitude of home delivery of the respondents}

This study revealed that about71.0\% (95\% CI, 65.8\%$75.8 \%$ ) of women delivered at home and majority of them were assisted by non-skilled attendants $(75.4 \%)$. This result was consistent with other studies conducted in Wukro and Butajira districts (75.0\%) and Arbaminch Zuria district (79.4\%) [34,35]; but lower than a study conducted in Munesa district, Oromiya region (87.7\%) mini EDHS (2014) report (90.0\%), Sekela district, Amhara region $(87.9 \%)[1,23,36]$ and higher than the result from Woldia district, Amhara region (51.7\%) [20]. This difference could partly be explained by their differences in socioeconomic, geographical location and the time gap between the studies of the study populations.

\section{Factors associated with home delivery of the respon- dents}

This study identifiedvarious predictors for home delivery; those are socio-demographic factors like mother's age, mother's residence, mother's educational status and obstetric factors like awareness on at least one danger signs during pregnancy and delivery of the women.

Mainly, women who are living in the rural areas were 7.3 times more likely to deliver at home than women living in the urban areas $(\mathrm{AOR}=7.29,95 \% \mathrm{CI}=6.89-13.41)$. The reason for these might be due the fact that in rural areas proportion of mothers with education is low, inaccessibility of the services with long distance and transport, and mothers could not have better decision making autonomy and better access to information than urban mothers. Similar findings were found in the study done in Sekela and Goba districts [31,36].

Educational status of the women was an important predictor for home delivery; women who had no formal education were 2.8 more likely to deliver in their home than women who had formal education $(\mathrm{AOR}=2.83,95 \% \mathrm{CI}=1.1-7.5)$. The reason for this might be due the fact that when mothers have some level of formal education, it is more is likely to enhance female empowerment so that mothers develop decision making power regarding their own as well as their children health. 
Additionally, it is more likely that educated women demand higher quality service and be aware of difficulties/complications during pregnancy as well as child birth and as a result, they are more likely to use maternal health care services unlike that

Table 3: History of the recent home and institutional delivery of the study participants Aysaita district, Afar region, North Eastern, Ethiopia, 2016 ( $n=317)$.

\begin{tabular}{|c|c|}
\hline Variable(s) & Freque \\
\hline Place of delivery & Home \\
\hline Health facility & \\
\hline Reasons for home delivery ( $\mathbf{n}=\mathbf{2 2 5})$ & \\
\hline No health problem & \\
\hline No female health worker & \\
\hline Health facility is far & \\
\hline Husband refused & \\
\hline High cost & \\
\hline Poor quality of service & \\
\hline Feel shame & \\
\hline Others & \\
\hline
\end{tabular}

Who assisted you during home delivery

Trained Traditional birth attend

Health extension worker

Mother
Relative
Others

Did you faced any health problem during labor and delivery

$$
\text { Yes }
$$$$
\text { No }
$$

225

92

71.0

29.0

85

37.8

6.2

31.1

.9

0.9

15.1

7.6

0.4

26.1

24.6

39.3

9.5

0.5

1

88

229

Types of health problem during labor and delivery $(n=88)$

Ante partum hemorrhage

Excess bleeding during labor

Intrauterine fetal death

Elevated blood pressure

Others

\section{Duration of labor}

Less than half a day

One day or one night

More than one and half day

new born status after delivery

Alive

Alive but died immediately

Dead fetus

Other situation

Any health problem of the alive baby

$(n=309)$

Yes

No

286

27

70

Husband

Jointly

Others
Table 4: Socio-demographic factors associated with home delivery among the study participants from the bivariate logistic regression analysis, in Assaita District, North Eastern, Ethiopia, March, 2016(n=317).

\begin{tabular}{|c|c|c|c|}
\hline \multirow{2}{*}{ Variable (s) } & \multicolumn{3}{|c|}{ Place of delivery } \\
\hline & Home (\%) & Health facility (\%) & COR $(95 \% \mathrm{Cl})$ \\
\hline \multicolumn{4}{|l|}{ Mother's age (years) } \\
\hline$<25$ & $94(81.0)$ & $22(19.0)$ & $2.283(1.321-3.947)$ \\
\hline$>=25$ & $131(65.2)$ & $70(34.8)$ & 1 \\
\hline \multicolumn{4}{|l|}{ Religion } \\
\hline Muslim & $208(70.3)$ & $88(29.7)$ & $0.556(0.182-1.700)$ \\
\hline Others & $17(81.0)$ & $4(19.0)$ & 1 \\
\hline \multicolumn{4}{|l|}{ Residence } \\
\hline Rural & $208(79.1)$ & $55(20.9)$ & $8.231(4.312-15.713)$ \\
\hline Urban & $17(31.5)$ & $37(68.5)$ & 1 \\
\hline \multicolumn{4}{|l|}{ Mother's education } \\
\hline No formal education & $178(75.1)$ & $59(24.9)$ & $2.118(1.242-3.612)$ \\
\hline Formal education & $47(58.8)$ & $33(41.2)$ & 1 \\
\hline \multicolumn{4}{|l|}{ Mother's occupation } \\
\hline Housewife & $212(70.9)$ & $87(29.1)$ & $0.937(.324-2.708)$ \\
\hline Working & $13(72.2)$ & $5(27.8)$ & 1 \\
\hline \multicolumn{4}{|l|}{ Mother's marital status } \\
\hline Currently married & $211(71.3)$ & $85(28.7)$ & $1.241(0.484-3.182)$ \\
\hline Currently unmarried & $14(66.7)$ & $7(33.3)$ & 1 \\
\hline \multicolumn{4}{|l|}{ Husband's education } \\
\hline No formal education & $122(70.1)$ & $52(29.9)$ & $0.870(0.520-1.456)$ \\
\hline Formal education & $89(73.0)$ & $33(27.0)$ & 1 \\
\hline \multicolumn{4}{|l|}{ Husband's occupation } \\
\hline Pastoralist & $80(76.9)$ & $24(23.1)$ & 1 \\
\hline Non-pastoralist & $131(68.2)$ & $61(31.8)$ & $0.644(.372-1.115)$ \\
\hline
\end{tabular}

the illiterate one. The result of this study is consistent with other studies conducted in Wukro Butajira, Arbaminch Zuria and Sekela districts of other region [34-36].

Age of the women was also strong predictor for home delivery; women who are less than 25 years were 2.9 times more likely to deliver at home than women having age greater than 25 years $(\mathrm{AOR}=2.9,95 \% \mathrm{CI}=1.1-8.1)$. This indicates that older women had a higher chance of delivery in health facilities than their younger counterparts. The relations between age and home delivery in the literature have conflicting findings. Other studies have reported that older women may believe that there is less risk to home delivery due to previous uneventful pregnancies and deliveries [35]. On the other hand, obstetric complications may increases with age as a result of older women may use health facility for delivery than younger women [34]. Which is similar to the present study. Hence, ANC visits foryounger mothers should focus on the benefits of institutional delivery as well as the unpredictability of risks and complications during the course of pregnancy and delivery.

Furthermore, in this study awareness on at least one danger signs during pregnancy and delivery was a predictor for home delivery; that women who had not awareness on at least one danger signs during pregnancy and delivery were 3.3 times more likely to be delivered at home as compared to women who had some level of awareness on these danger signs (AOR=3.30, 
Table 5: Maternal and obstetric factors associated with home delivery among the study participants from the bivariate logistic regression analysis, in Assaita District, North Eastern, Ethiopia, March, 2016(n=317).

\begin{tabular}{|c|c|c|c|}
\hline \multirow{2}{*}{ Variable (s) } & \multicolumn{3}{|c|}{ Place of delivery } \\
\hline & Home (\%) & Health facility (\%) & COR $(95 \% \mathrm{Cl})$ \\
\hline \multicolumn{4}{|l|}{ Age at first pregnancy } \\
\hline$<18$ & $55(73.3)$ & $20(26.7)$ & $0.873(0.485-1.571)$ \\
\hline $18-24$ & $156(70.6)$ & $65(29.3)$ & $0.727(0.257-2.061)$ \\
\hline$>24$ & $14(66.7)$ & $7(33.3)$ & 1 \\
\hline \multicolumn{4}{|l|}{ Gravidity } \\
\hline Primigravida & $55(82.1)$ & 12(17.9) & $2.157(1.094-4.252)$ \\
\hline Multigravida & $170(68.0)$ & $80(32.0)$ & 1 \\
\hline \multicolumn{4}{|l|}{ Parity } \\
\hline Primiparous & $55(77.5)$ & $16(22.5)$ & $1.537(0.828-2.854)$ \\
\hline Multiparous & $170(69.1)$ & $76(30.9)$ & 1 \\
\hline \multicolumn{4}{|l|}{ Wanted pregnancy } \\
\hline Yes & 194(72.7) & $73(27.3)$ & 1 \\
\hline No & $31(62.0)$ & 19(38.0) & $0.614(0.327-1.154)$ \\
\hline \multicolumn{4}{|l|}{ Attended ANC } \\
\hline Yes & 172(72.9) & $64(27.1)$ & 1 \\
\hline No & $53(65.4)$ & 28(34.6) & $0.704(0.410-1.209)$ \\
\hline \multicolumn{4}{|l|}{ Place of ANC attendance } \\
\hline Hospital & $82(80.4)$ & 20(19.6) & $1.640(0.296-9.076)$ \\
\hline Health center & $85(66.9)$ & $42(33.1)$ & $0.810(0.151-4.348)$ \\
\hline Others( such as health Post) & $5(71.4)$ & $2(28.6)$ & 1 \\
\hline \multicolumn{4}{|l|}{ GA at first ANC service } \\
\hline$<=16$ weeks & $147(75.0)$ & $49(25.0)$ & 1 \\
\hline$>16$ weeks & $25(65.5)$ & $15(37.5)$ & $0.556(0.271-1.138)$ \\
\hline \multicolumn{4}{|l|}{ Frequency of ANC visit } \\
\hline$<4$ & $109(72.2)$ & $42(27.8)$ & $0.906(0.496-1.654)$ \\
\hline$>=4$ & $63(74.1)$ & $22(25.9)$ & 1 \\
\hline \multicolumn{4}{|l|}{ No of live births } \\
\hline $0-1$ & $62(78.5)$ & $17(21.5)$ & $2.288(1.142-4.586)$ \\
\hline $2-3$ & 112(72.3) & $43(27.7)$ & $1.634(0.929-2.875)$ \\
\hline$>3$ & $51(61.4)$ & $32(38.6)$ & 1 \\
\hline \multicolumn{4}{|l|}{ No of abortions } \\
\hline 0 & 198(71.2) & $80(28.8)$ & 1 \\
\hline$>=1$ & $27(69.2)$ & $12(30.8)$ & $0.909(0.439-1.882)$ \\
\hline \multicolumn{4}{|l|}{ No of neonatal death } \\
\hline 0 & 196(70.8) & $81(29.2)$ & 1 \\
\hline$>-1$ & $29(72.5)$ & $11(27.5)$ & $1.090(0.519-2.285)$ \\
\hline \multicolumn{4}{|l|}{$\begin{array}{l}\text { Awareness on at least one } \\
\text { danger signs during } \\
\text { pregnancy and delivery }\end{array}$} \\
\hline Yes & $110(75.3)$ & $36(24.7)$ & 1 \\
\hline No & $115(67.3)$ & $56(32.7)$ & $0.672(0.410-1.101)$ \\
\hline \multicolumn{4}{|l|}{$\begin{array}{l}\text { Have you faced any health } \\
\text { problem }\end{array}$} \\
\hline Yes & $69(78.4)$ & 19(21.6) & $1.699(0.953-3.032)$ \\
\hline No & $156(68.1)$ & $73(31.9)$ & 1 \\
\hline \multicolumn{4}{|l|}{ Duration of labor } \\
\hline Less than half a day & 197(72.2) & $76(27.8)$ & 1 \\
\hline One day or one night & 19(70.4) & $8(29.6)$ & $0.916(0.385-2.181)$ \\
\hline More than one and half day & $9(52.9)$ & $8(47.1)$ & $0.434(0.162-1.166)$ \\
\hline \multicolumn{4}{|l|}{$\begin{array}{l}\text { Decision maker for place of } \\
\text { delivery }\end{array}$} \\
\hline Self & $21(77.8)$ & $6(22.2)$ & $1.599(0.618-4.139)$ \\
\hline Husband & $53(75.7)$ & $17(24.3)$ & $1.425(0.769-2.638)$ \\
\hline Jointly & $151(68.6)$ & $69(31.4)$ & 1 \\
\hline
\end{tabular}

Table 6: Factors associated with institutional delivery service among the study participants from multivariable logistic regression analysis, in Assaita district, Afar regional state, North Eastern Ethiopia, 2016(n=317).

\begin{tabular}{|c|c|c|c|c|}
\hline \multirow[b]{2}{*}{ Variable (s) } & \multicolumn{4}{|c|}{ Place of delivery } \\
\hline & Home (\%) & $\begin{array}{c}\text { Health } \\
\text { facility } \\
(\%)\end{array}$ & COR $(95 \% \mathrm{Cl})$ & AOR $(95 \% \mathrm{Cl})$ \\
\hline \multicolumn{5}{|l|}{$\begin{array}{l}\text { Mother's age } \\
\text { (years) }\end{array}$} \\
\hline$<25$ & $94(81.0)$ & $22(19.0)$ & 2.283(1.321-3.947) & $2.959(1.076-8.133)^{\star}$ \\
\hline$>=25$ & $131(65.2)$ & $70(34.8)$ & 1 & 1 \\
\hline \multicolumn{5}{|l|}{ Residence } \\
\hline Rural & $208(79.1)$ & 55 (20.9) & $8.231(4.312-15.713)$ & $7.29(6.89-13.41)^{\star}$ \\
\hline Urban & $17(31.5)$ & $37(68.5)$ & 1 & 1 \\
\hline \multicolumn{5}{|l|}{$\begin{array}{l}\text { Mother's } \\
\text { education }\end{array}$} \\
\hline $\begin{array}{l}\text { No formal } \\
\text { education }\end{array}$ & $178(75.1)$ & $59(24.9)$ & $2.118(1.242-3.612)$ & $2.838(1.073-7.506)^{\star}$ \\
\hline Formal education & $47(58.8)$ & $33(41.2)$ & 1 & 1 \\
\hline \multicolumn{5}{|l|}{$\begin{array}{l}\text { Husband's } \\
\text { occupation }\end{array}$} \\
\hline Pastoralist & $80(76.9)$ & $24(23.1)$ & 1 & 1 \\
\hline Non-pastoralist & $131(68.2)$ & $61(31.8)$ & $0.644(.372-1.115)$ & $2.039(0.846-4.912)$ \\
\hline \multicolumn{5}{|l|}{ Gravidity } \\
\hline Primigravida & $55(82.1)$ & 12(17.9) & $2.157(1.094-4.252)$ & $2.187(0.633-7.551)$ \\
\hline Multigravida & $170(68.0)$ & $80(32.0)$ & 1 & 1 \\
\hline \multicolumn{5}{|l|}{ Parity } \\
\hline Primiparous & $55(77.5)$ & $16(22.5)$ & $1.537(0.828-2.854)$ & $1.759(0.740-4.180)$ \\
\hline Multiparous & $170(69.1)$ & $76(30.9)$ & 1 & 1 \\
\hline \multicolumn{5}{|l|}{ Wanted pregnancy } \\
\hline Yes & 194(72.7) & $73(27.3)$ & 1 & 1 \\
\hline No & $31(62.0)$ & 19(38.0) & $0.614(0.327-1.154)$ & $0.030(0.001-1.156)$ \\
\hline \multicolumn{5}{|l|}{ Attended ANC } \\
\hline Yes & 172(72.9) & $64(27.1)$ & 1 & 1 \\
\hline No & $53(65.4)$ & $28(34.6)$ & $0.704(0.410-1.209)$ & $0.514(0.202-1.311)$ \\
\hline \multicolumn{5}{|l|}{$\begin{array}{c}\text { GA at first ANC } \\
\text { service }\end{array}$} \\
\hline$<=16$ weeks & $147(75.0)$ & $49(25.0)$ & 1 & 1 \\
\hline$>16$ weeks & $25(65.5)$ & $15(37.5)$ & $0.556(0.271-1.138)$ & $0.752(0.284-1.997)$ \\
\hline \multicolumn{5}{|l|}{ No of live births } \\
\hline $0-1$ & $62(78.5)$ & $17(21.5)$ & $2.288(1.142-4.586)$ & $1.527(0.617-3.781)$ \\
\hline $2-3$ & $112(72.3)$ & $43(27.7)$ & 1.634(0.929-2.875) & $1.774(0.690-4.563)$ \\
\hline$>3$ & $51(61.4)$ & $32(38.6)$ & 1 & 1 \\
\hline \multicolumn{5}{|l|}{$\begin{array}{l}\text { Awareness on at } \\
\text { least one danger } \\
\text { signs during } \\
\text { pregnancy }\end{array}$} \\
\hline Yes & $110(75.3)$ & $36(24.7)$ & 1 & 1 \\
\hline No & $115(67.3)$ & $56(32.7)$ & 0.672(0.410-1.101) & 3.306(1.346-8.119)* \\
\hline \multicolumn{5}{|l|}{$\begin{array}{l}\text { Have you faced } \\
\text { any health } \\
\text { problem }\end{array}$} \\
\hline Yes & $69(78.4)$ & 19(21.6) & 1.699(0.953-3.032) & $1.809(0.723-4.525)$ \\
\hline No & $156(68.1)$ & 73(31.9) & 1 & 1 \\
\hline${ }^{*}(p<0.05$ is signifi & & & & \\
\hline
\end{tabular}

$95 \% \mathrm{CI}=1.35,8.12)$. The reason for these might be due the fact that women that have some level of knowledge on danger signs might have perceived service benefits of a health institution, like complication management by skilled health care workers during labor. The result of this study is consistent with other 
studies conducted in Dangila, Banja and Sekela Districts $[4,36,37]$.

\section{Strength of the study}

The major strengths of this study were: community based including the urban and rural areas who gave birth in the last 12 months.

\section{Limitation of the study}

There might be the possibility of recall bias. However, we tried to minimize by focusing on those women who gave birth in the last one year.

This study used quantitative approach which could not address the "why" questions in detail. Therefore further studies should focus on qualitative approach to come up with additional findings.

\section{Conclusion}

This study revealed that home delivery in last 12 months preceding the survey was high. Majority of women $(74.4 \%)$ attended at least one antenatal visit from skilled health care providers during their recent pregnancy but majority of them gave birth at home (71.0\%) and assisted by non-skilled attendant. Women's residence (being rural), literacy status (being illiterate), age (having age less than 25 years old) and awareness on at least one danger signs during pregnancy and delivery (not having awareness) were the independent predictors for home delivery among the study subjects. Being apparently healthy (37.8\%), distant of health facility (31.1\%), and poor quality of healthservice $(15.1 \%)$ were the main reasons given by the women for home delivery.

Hence it is recommended that the district education offices should strengthen access for women to education by establishing the appropriate schools within the reach of rural and pastoral community. The health extension workers should create awareness about the importance of institutional delivery; Health extension workers should assist the pregnant women for birth preparedness in the institution particularly for the rural pastoralist mothers. District health office should increase coverage of health institution to decrease distant of the rural areas by establishing the suitable delivery facility centers within the reach to the rural pregnant women.

\section{Acknowledgments}

We are thankful to Samara University jointly with Mekelle University for provide such an opportunity to conduct this study.

\section{References}

1. Abdella A, Abebaw G, Zelalem B (2012) Institutional delivery service utilization in Munisa Woreda, South East Ethiopia: a community based cross-sectional study. BMC Pregnancy and Childbirth. Link: https://goo.gl/gVJ1LP

2. Addis AF, Meaza D (2012) Prevalence of institutional delivery and associated factors in Dodota Woreda, Oromiya regional state, Ethiopia. Reproductive Health. Link: https://goo.gl/XoM6C8
3. Adisasmita A, Deviany PE, Nandiaty F, Stanton C, Ronsmans C (2008) Obstetric near miss and deaths in public and private hospitals in Indonesia. BMC Pregnancy and Childbirth. Link: https://goo.gl/AjfvXn

4. Alemaw W, Mekonnen A, Worku A (2014) Institutional delivery service utilization and associated factors in Banja District, Awie Zone, Amhara Regional Sate, Ethiopia: Open Journal of Epidemiology 4: 30-35. Link: https://goo.gl/UDkDvh

5. Mrisho M, Schellenberg JA, Mushi AK, Obrist B, Mshinda H, et.al. (2017) D: Factors affecting home delivery in rural Tanzania. Tropical Medicine \& International Health 12: 862-872. Link: https://goo.gl/1BVUyE

6. Ronsmans C, Graham WJ (2006) on behalf of The Lancet Maternal Survival Series steering group: Maternal mortality: who, when, where, and why. Lancet 368: 1189-1200. Link: https://goo.gl/nA89cU

7. Kyomuhendo GB (2003) Low use of rural maternity services in Uganda: impac of women's status, traditional beliefs and limited resources. Reproductive Health Matters 11: 16-26. Link: https://goo.gl/uiUBJs

8. Lawn JE, Lee AC, Kinney M, Sibley L, Carlo WA, et al. (2009) Two million intrapartum-related stillbirths and neonatal deaths: where, why, and what can be done? Int J Gynaecol Obstet 107: 18-19. Link: https://goo.gl/eVXExW

9. Wahed T, Moran A, Iqbal M (2010) the perspectives of clients and unqualified allopathic practitioners on the management of delivery care in urban slums, Dhaka, Bangladesh - A mixed method study. BMC Pregnancy Childbirth Link: https://goo.gl/aUvb5F

10. Gurmesa T, Abebe G (2008) Safe delivery service utilization in Metekel zone North West Ethiopia. Ethiopia Journal of Health Science 17: 213-222. Link: https://goo.gl/DnJhxZ

11. (2012) Central Statistical Agency [Ethiopia], ICF International: Ethiopia Demographic and Health Survey 2011. Addis Ababa, Ethiopia and Calverton, Maryland, USA: Central Statistical Agency and ICF International. Link: https://goo.gl/S3ucYq

12. Mekonnen M, Yalew K, Umer J, Melese (2012) Determinants of delivery practices among Afar pastoralists of Ethiopia. Pan Afar Med J. Link: https://goo.gl/JMCZEW

13. Idris S, Gwarzo U, Shehu A (2006) Determinants of Place of Delivery among Women in a Semi- Urban Settlement in Zaria, Northern Nigeria. Ann of Afric Med 5: 68-72. Link: https://goo.gl/VusweR

14. (1994) ICPD (International Conference on Population and Development) Program of action adopted at the International Conference on Population and Development Cairo5-13 September. Link: https://goo.gl/wrga4R

15. Friberg I, Kinney M, Lawn J, Kerber K, Odubanjo M, et al. Sub-Saharan Africa's mothers, newborns, and children: how many lives could be saved with targeted health. Link: https://goo.gl/UnjGWR

16. Kinney MV, Kerber KJ, Black RE, Cohen B, Nkrumah F, et al. (2010) SubSaharan Africa's mothers, newborns, and children: where and why do they die? PLoS Med. Link: https://goo.gl/stCBQT

17. Carroli G, Villar J, Piaggio G, Khan-Neelofur D, Gülmezoglu M, et al. WHO systematic review of randomized controlled trials of routine antenatal care. Lancet. Link: https://goo.gl/8Yjymj

18. (2010) WHO (World Health Organization). World health statistics. WHO. Link: https://goo.gl/N4h3Z5

19. Lawn JE, Lee AC, Kinney M, Sibley L, Carlo WA, et al. (2009) Two million intrapartum-related stillbirths and neonatal deaths: where, why, and what can be done? Int J Gynaecol Obstet 107:18-19. Link: https://goo.gl/bk1 d5v

20. Worku Awoke, Jemal Muhammed, Gedefaw Abeje (2013) Institutional Delivery Service Utilization in Woldia, Ethiopia; Science Journal of Public Health. 1: 18-23. Link: https://goo.gl/CHRXBX 
21. Henock Y, Mussie A, Alemayehu K (2014) Individual and community-leve predictors of women's decision on place of delivery: A multilevel mixedeffects analysis on Ethiopia National Demography and Health Survey. Link: https://goo.gl/4UugAT

22. Yared M, Asnakech M (2013) Factors Influencing the Use of Maternal Healthcare Services in Ethiopia Journal of Health Population Nutrition; 21:374-382. Link: https://goo.gl/eTjRvd

23. (2014) Central Statistical Agency [Ethiopia]. Ethiopia Mini Demographic and Health Survey 2014. Addis Ababa, Ethiopia. Link: https://goo.gl/VSpHFV

24. Mrisho M, Schellenberg JA, Mushi AK, Obrist B, Mshinda H, et.al. (2007) Factors affecting home delivery in rural Tanzania. Tropical Medicine \& International Health 12: 862-872. Link: https://goo.gl/8wHRE7

25. Magoma M, Requejo J, Campbell OM, Cousens S, Filippi V (2010) High ANC coverage and low skilled attendance in a rural Tanzanian district: a case for implementing a birth plan intervention. BMC Pregnancy Childbirth. Link: https://goo.gl/ShsgqD

26. Ugo O, Mohammed J, Muhammad A., Isa S, Nonye A, et.al. (2012) Prenata care and basic emergency obstetric care services provided at primary healthcare facilities in rural Nigeria; International Journal of Gynecology and Obstetrics 117: 61-65. Link: https://goo.gl/iNyZtE

27. Amon E, Almamy MK, Mustafa N, Kassimu T, et.al. (2014) Access to institutional delivery care and reasons for home delivery in three districts of Tanzanialnternational Journal for Equity in Health 13:48. Link: https://goo.gl/SsDCfd

28. (2010) Yvonne analysis of Rwandan demographic health survey, international journal of scientific and technology research. Link: https://goo.gl/PFMhbo

29. Niguse $\mathrm{M}, \mathrm{H} /$ Mariam $\mathrm{H}$, Mitke $\mathrm{G}$ (2004) assessment of safe delivery service utilization among women of child bearing age in North Gondar Zone. Ethiop.J.health.Dev 18: 145-152. Link: https://goo.gl/CqaqDR
30. Worku A, Jemal M, Gedefaw A (2013) Institutional Delivery Service Utilization in Woldia, Ethiopia; Science Journal of Public Health. Link: https://goo.gl/G9Qgh2

31. Daniel B, Desalegn M (2014) Institutional delivery service utilization and associated factors among child bearing age women in Goba Woreda, Ethiopia; Journal of Gynecology and Obstetrics 63-70. Link: https://goo.gl/TsgJfS

32. Yalem T, Tesfay G, Isabel G, Kerstin E, Hailemariam L, et.al. (2013) Determinants of antenatal and delivery care utilization in Tigray region, Ethiopia: a cross-sectional study; International Journal for Equity in Health. Link: https://goo.gl/U3dCnF

33. Melkamu $F$ (2006) factors for influencing utilization of maternal health care service in Ayssaita district, Ethiopia, science journal of public health. Link: https://goo.gl/BZjnrA

34. Wukro, Butajira HS, Shaweno D, Assegid M et.al. (2014) Utilization of institutional delivery service at Wukro and Butajera districts in the Northern and South Central Ethiopia. BMC pregnancy and childhealth 14: 178. Link: https://goo.gl/pHfh18

35. Arbaminch Gistane Ayele, Maralign Tilahune, Behailu Merdikyos, Worku Animaw, Wondimagegn Taye. (2015). Prevalence and Associated Factors of Home Delivery in Arbaminch Zuria District, Southern Ethiopia: Community Based Cross Sectional Study. Science Journal of Public Health. Link: https://goo.gl/XFLfwf

36. Sekela SA, Mazengia F, Meseret S (2012) Institutional delivery service utilization and associated factors among mothers who geve birth in the last 12 months in Sekela district.BMC pregnancy and childhealth. Link: https://goo.gl/fWoRR9

37. Dangila Demilew YM, Gebregergs GB, Negusie AA (2016) Factors associated with institutional delivery in Dangila District, North West Ethiopia: a crosssectional study. Afri Health Sci 16: 10-17.Link: https://goo.gl/W1SZLE

Copyright: (C) 2017 Abdella M, et al. This is an open-access article distributed under the terms of the Creative Commons Attribution License, which permits unrestricted use, distribution, and reproduction in any medium, provided the original author and source are credited. 